\title{
Acellular dermal matrix in soft tissue reconstruction prior to bone grafting. A case report
}

\author{
Vanessa Ruiz-Magaz ${ }^{1}$, Federico Hernández-Alfaro ${ }^{2,3}$, Artur Díaz-Carandell ${ }^{3}$, María-José Biosca-Gómez de \\ Tejada $^{3}$ \\ ${ }^{1}$ DDS. Master in Periodontics, Associate Professor in Periodontology, Universitat Internacional de Catalunya \\ ${ }^{2}$ MD, DDS, FEBOMS, PhD. Director of the program in Implant Dentistry, Universitat Internacional de Catalunya \\ ${ }^{3}$ MD. Specialist in Oral and Maxillofacial Surgery. Associate Professor in Implant Dentistry. Universitat Internacional de Cata- \\ lunya
}

Correspondence:

Instituto de Cirugía Maxilofacial e Implantología;

Centro Médico Teknon

C/Vilana 12

08022, Barcelona, Spain,

vruiz@lleida.org.

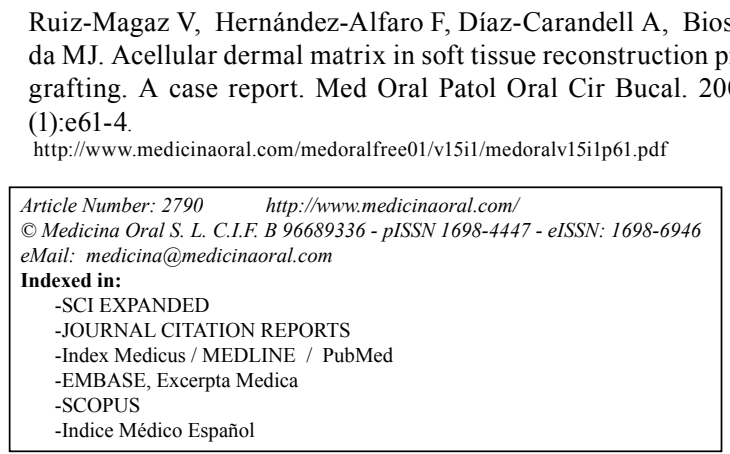

\begin{abstract}
When hard tissue augmentation is scheduled as a part of an oral rehabilitation, prior to the treatment, it is important to assess if the quality of the underlying gingiva at the recipient site can support the bone grafting procedure. The most frequent complication during autologous onlay grafts are wound dehiscences in the recipient site, so the integrity of soft tissues is a basic aspect of successful reconstructive and plastic surgical procedure. Connective tissue grafts can improve the quality and quantity of soft tissue in oral sites where a hard tissue reconstruction is going to take place. However, particularly when large grafts are harvested, the autogenous donor site can present significant postoperative morbidity, such as necrosis of the palate fibromucosa and bone exposition, pain and bleeding. Another important limitation with the use of autogenous grafts is the limited supply of donor connective tissue. If a large site needs to be grafted, more than one surgical procedure may be required. An Acellular Dermal Matrix (ADM) graft has become increasingly popular as a substitute for donor connective tissue, eliminating the disadvantages described for the autogenous donor graft. The amount of tissue harvested is unlimited, so it gives an option for treating patients that have inadequate harvestable tissue or that present a large defect to be treated. The outcome of using ADM as a matrix for soft tissue reconstruction 12 weeks before bone grafting can reduce the risk of exposure and failure of the bone graft.
\end{abstract}

Key words: Acellular Dermal Matrix, bone graft, soft tissue reconstruction. 


\section{Introduction}

Deformities of the dentoalveolar ridge are usually the result of developmental defects, periodontal disease, trauma, or surgical insult. When hard tissue augmentation is scheduled it is necessary to assess soft tissue features at the recipient site. It's important to determine whether the quality of the soft tissue is adecuate to support an underlying bone reconstruction. The integrity of soft tissues is thus a basic aspect of successful reconstructive and plastic surgical procedures. A variety of predictable and aesthetically acceptable mucogingival grafting procedures using autogenous tissue exist for gingival augmentation. The insertion of a connective tissue graft, can improve the quality and quantity of soft tissue prior to the bone augmentation (1-4). The palate is the usual source for connective tissue grafts and there can be significant postoperative morbidity, particularly when large grafts are harvested (5). An Acellular Dermal Matrix (ADM; Alloderm, BiohorizonsR) graft has become increasingly popular as a substitute for donor connective tissue, eliminating the disadvantages described for the autogenous donor graft. The amount of tissue harvested is unlimited so it gives an option for treating patients that have inadequate harvestable tissue.

The aim of this report is to present the outcome of a patient treated with ADM used as a matrix for soft tissue reconstruction as the first step of the oral reconstruction that was performed.

\section{Case report}

A 53-year-old, nonsmoking female with no contributory systemic history was scheduled to receive a rehabilitation at the maxillary aesthetic zone. A volumetric tomographic scan revealed the atrophic condition; she presented a type-III alveolar-ridge defect according to Seibert's classification (1983) (6). Periimplantitis in three implants in the maxilla aesthetic zone was also present. As part of the treatment plan, she was scheduled to receive an autogenous bone graft; however, she presented an inadequate volumetric size of the queratinized gingiva that was going to be unable to support that reconstruction (Fig. 1). Moreover, the implants placed in the area presented periimplantitis so we decided to withdraw them so some more secondary soft tissue collapse of the area was expected. Preventing ridge collapse should be avoided using socket preservation techniques using ADM and a xenograft. It was determined to perform surgical treatment in two stages: Implants were going to be removed and soft tissues would be improved by placing the allograf. At a second stage, hard tissue reconstruction was going to be performed. The patient would subsequently receive dental implants in the edentulous section.

The area was anaesthetized with $2 \%$ lidocaine with epinephrine 1:100000 using the infiltration technique. A full-thickness flap was developed from the distal line angle of the maxillary right canine to the distal line angle of the maxillary left first premolar with a $15 \mathrm{c}$ surgical blade.

After the explantation of the fixtures with a trephine, an important bleeding from the nasal floor was noticed so some hemostatic dressing (Surgicel ${ }^{\circledR}$ ) was used in order to achieve haemosthasis at this site. The bony defects at the implant areas were filled with bovine xenograft in order to prevent further ridge collapse. Therefore, to protect the bone xenograft from being exposed and to increase the quantity of soft tissue a $1 \mathrm{X} 4-\mathrm{cm}$ piece of ADM was used (Fig. 2). This material was rehydrateted twice, for 10 minutes each time, with saline. No direct stabilization of the material with screws was carried out in this case. After performing releasing incisions at the base of the flap, the ADM was completely covered. In some areas the ADM remained exposed at the sites of the previous implants. The patient was given postoperative instructions on how to care the surgical site and was prescribed decreasing doses of corticosteroids for 3 days $(60 \mathrm{mg}$ on the first day, $40 \mathrm{mg}$ on the second day and $20 \mathrm{mg}$ on the third day), $600 \mathrm{mg}$ of ibuprofen every 8 hours for 7 days, $500 \mathrm{mg}$ of amoxicillin every 8 hours for 7 days and chlorhexidine gel three times a day for 15 days.

The patient was examined 6 and 10 days after surgery and the revascularization of the graft and the healing of the surgical site were monitored. The sutures were removed after 15 days. The patient was instructed to wear a provisional prosthesis from the first day after the surgery and was then examined 4, 8 and 12 weeks after surgery. It was observed that the therapeutic goals had

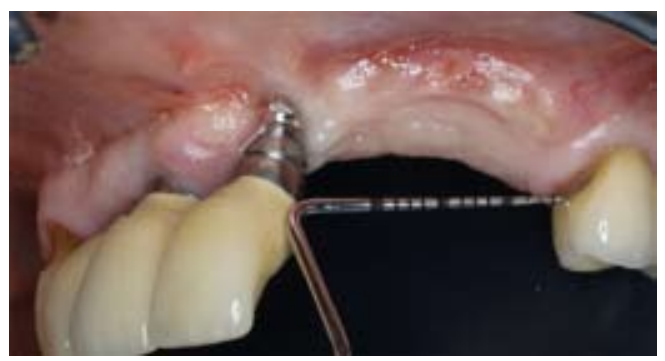

Fig. 1. Preoperative view: inadequate volumetric size of queratinized gingiva.

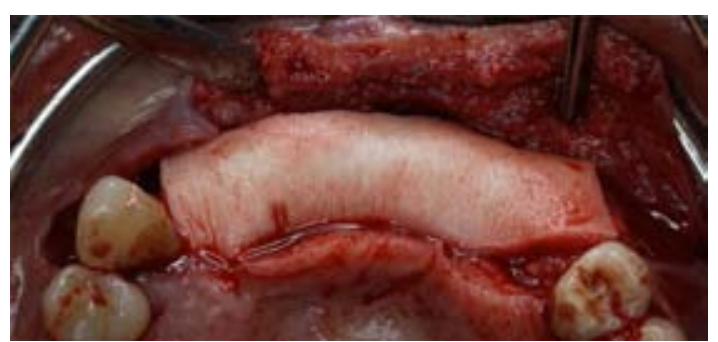

Fig. 2. $1 \mathrm{X}$ 4-cm piece of ADM placed to correct the gingiva defect. 


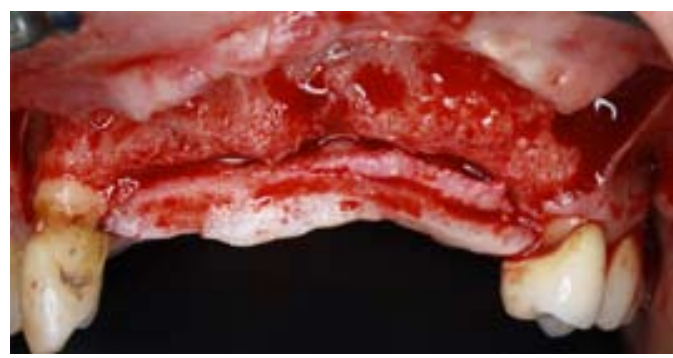

Fig. 3. Re-entry for hard tissue augmentation three months later.

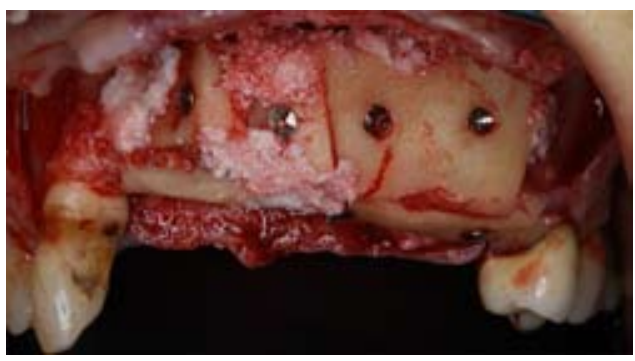

Fig. 4. Onlay bone grafts posicioned on the premaxilla and fixed with screws.

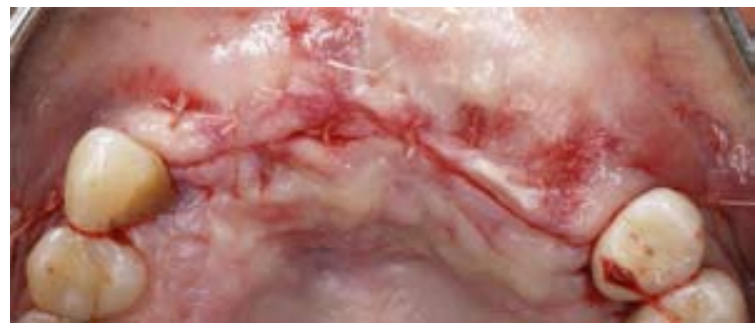

Fig. 5. Primary closure of the surgical site achieved without exposition of the onlay bone graft.

been achieved, given that the amount of gingiva was increased around the edentulous alveolar ridge.

We consider to perform a two-step procedure to achieve soft and hard tissue reconstruction because both ADM and autogenous bone grafts need to be revascularizated. This two-step surgical model may improve the revascularization of each graft because they don't have to compete for the blood supply.

Hard tissue augmentation was performed, three months later. The recipient site presented a thick gingival biotipe. After onlay bone grafts were harvested from the right ascending ramus, they were positioned on the premaxilla and fixed with screws. The intervening area was then filled with xenograft (Bio-Oss, Geistlich Biomaterials )and covered by a collagen reabsorvable membrane (Bio-Gide, Geistlich Biomaterials)(Fig. 3 and 4). A partial-thickness dissection was then made at the base of the vestibular flap, so primary closure of the surgical wound was achieved (Fig. 5).

\section{Discussion}

Augmentation procedures using autologous onlay grafts are indicated when the height of the alveolar crest is less than $5 \mathrm{~mm}$, or the width less than $4 \mathrm{~mm}$. The most frequent complications in the recipient site are wound dehiscences (7). Multiple investigations have documented esthetic results using ADM equivalent to autologous connective tissue because it serves as a scaffold for epithelial cell migration, thus allowing pigmentation and contour to emulate surrounding tissues (8-10). Batista et al. presented a investigation where they evaluated the use of ADM in the treatment of soft tissue ridge defects. Eight patients provided 18 sites corresponding to missing teeth in the anterior maxillary arch. After raising partial-thickness flaps, the ADM material was folded to fill the defect and reproduce the desired gain. Flaps were sutured with no tension, and part of the material was intentionally left exposed to avoid pressure on the incision line and prevent height loss. Clinically, the total gain in the subjects was very effective and matched the receptor tissues nicely. It was concluded that ADM could be a suitable material for the treatment of soft tissue ridge deformities due to its biocompatibility, color matching, and horizontal gain (11). Harris RJ , also reported a case to evaluate the use of ADM for soft tissue ridge augmentation. The technique used was a modification of the procedure proposed by Langer and Calagna and involved reflecting a partial-thickness pedicle, placing a ADM graft, and covering it with the pedicle. The increases in the quantity of tissue obtained were adequate to permit placing an esthetic fixed restoration in four of the five cases treated. So it was concluded that the use of ADM graft for soft tissue ridge augmentation was a clinically valuable technique (12).

ADM can also be used as a barrier membrane in ridge preservation. Luczyszyn et al. evaluated this role associated with a resorbable hydroxyapatite (RHA) in bone regeneration to prevent ridge deformities after tooth extraction. In the first group, the extractions were covered by ADM alone; and in the second group, the alveoli were filled with RHA before the placement of the ADM. After 6 months, re-entry surgeries and biopsies were performed. Although ridge thickness had been preserved in both groups, the means were significantly greater for the second group when compared to the first group. The histologic analysis showed small bone formation in some samples for group II, where the presence of a highly vascularized fibrous connective tissue surrounding the particles was a common finding. Based on the results, it was concluded that the ADM was able to preserve ridge thickness and that the additional use of RHA favored the preservation of the ridges along with an increase in the width of keratinized tissue (13).

Clinical results with ADM graft in periodontal surgeries suggest that the material is incorporated by the host 
tissues. Luczyszyn SM et al. evaluated the incorporation of ADM into gingival tissues in a dog model. Gingival recession-type defects were created at the canines of six dogs. After 6 weeks, periodontal surgeries to repair the defects were performed using ADM. Animals were sacrificed after 4,8 , and 12 weeks. At 4 weeks, thick collagen fibers from the ADM were clearly seen in the connective tissue, and some blood vessels were penetrating into the ADM. At 8 weeks, blood vessel penetration was enhanced, and collagen fiber bundles from the ADM were seen sending branches into the connective tissue in all directions. After 12 weeks, the ADM and the connective tissue seemed to be well integrated into a single highly vascularized structure, indicating almost complete incorporation of the ADM (14).

The two-step surgical model showed in this case report requires more time than the one-step proposed by Batista el al. 2001 but ensures the revascularization of each graft so the failure risk of the procedure is minimized (15). However clinical trials are necessary to evaluate the efficacy of ADM in bone grafting procedures.

\section{References}

1. Krüger E. Reconstruction of bone and soft tissue in extensive facial defects. J Oral Maxillofac Surg. 1982;40:714-20.

2. Frame JW, Browne RM, Brady CL. Biologic basis for interpositional autogenous bone grafts to the mandible. J Oral Maxillofac Surg. 1982;40:407-11.

3. Donn BJ Jr. The free connective tissue autograft: a clinical and histologic wound healing study in humans. J Periodontol. 1978;49:25360.

4. Edel A. Clinical evaluation of free connective tissue grafts used to increase the width of keratinised gingiva. J Clin Periodontol. 1974;1:185-96.

5. Imberman M. Gingival augmentation with an acellular dermal matrix revisited: surgical technique for gingival grafting. Pract Proced Aesthet Dent. 2007;19:123-8.

6. Seibert JS, Louis JV. Soft tissue ridge augmentation utilizing a combination onlay-interpositional graft procedure: a case report. Int J Periodontics Restorative Dent. 1996;16:310-21.

7. Maestre-Ferrín L, Boronat-López A, Peñarrocha-Diago M, Peñarrocha-Diago M. Augmentation procedures for deficient edentulous ridges, using onlay autologous grafts: an update. Med Oral Patol Oral Cir Bucal. 2009;14:e402-7.

8. Harris RJ. A comparative study of root coverage obtained with an acellular dermal matrix versus a connective tissue graft: results of 107 recession defects in 50 consecutively treated patients. Int $\mathrm{J}$ Periodontics Restorative Dent. 2000;20:51-9.

9. Tal H. Subgingival acellular dermal matrix allograft for the treatment of gingival recession: a case report. J Periodontol. 1999;70:111824.

10. Wei PC, Laurell L, Geivelis M, Lingen MW, Maddalozzo D. Acellular dermal matrix allografts to achieve increased attached gingiva. Part 1. A clinical study. J Periodontol. 2000;71:1297-305.

11. Batista EL Jr, Batista FC, Novaes AB Jr. Management of soft tissue ridge deformities with acellular dermal matrix. Clinical approach and outcome after 6 months of treatment. J Periodontol. 2001;72:265-73.

12. Harris RJ. Soft tissue ridge augmentation with an acellular dermal matrix. Int J Periodontics Restorative Dent. 2003;23:87-92.

13. Luczyszyn SM, Papalexiou V, Novaes AB Jr, Grisi MF, Souza SL, Taba M Jr. Acellular dermal matrix and hydroxyapatite in prevention of ridge deformities after tooth extraction. Implant Dent. 2005;14:176-84.

14. Luczyszyn SM, Grisi MF, Novaes AB Jr, Palioto DB, Souza SL, Taba M Jr. Histologic analysis of the acellular dermal matrix graft incorporation process: a pilot study in dogs. Int J Periodontics Restorative Dent. 2007;27:341-7.

15. Batista EL Jr, Batista FC. Managing soft tissue fenestrations in bone grafting surgery with an acellular dermal matrix: a case report. Int J Oral Maxillofac Implants. 2001;16:875-9. 